\title{
Two Clusters of GABAergic Ellipsoid Body Neurons Modulate Olfactory Labile Memory in Drosophila
}

\author{
Zhiping Zhang, ${ }^{1,2}$ Xiaoting Li, ${ }^{1,2}$ Jing Guo, ${ }^{1}$ Yan $\mathrm{Li},{ }^{1}$ and Aike Guo ${ }^{1,3}$ \\ ${ }^{1}$ State Key Laboratory of Brain and Cognitive Science, Institute of Biophysics, Chinese Academy of Sciences, Beijing 100049, People's Republic of China, \\ 2University of Chinese Academy of Sciences, Beijing 100049, People's Republic of China, and '3nstitute of Neuroscience, State Key Laboratory of \\ Neuroscience, Shanghai Institutes for Biological Sciences, Shanghai 200031, People's Republic of China
}

In Drosophila, aversive olfactory memory is believed to be stored in a prominent brain structure, the mushroom body (MB), and two pairs of MB intrinsic neurons, the dorsal paired medial (DPM) and the anterior paired lateral (APL) neurons, are found to regulate the consolidation of middle-term memory (MTM). Here we report that another prominent brain structure, the ellipsoid body (EB), is also involved in the modulation of olfactory MTM. Activating EB R2/R4m neurons does not affect the learning index, but specifically eliminates anesthesia-sensitive memory (ASM), the labile component of olfactory MTM. We further demonstrate that approximately two-thirds of these EB neurons are GABAergic and are responsible for the suppression of ASM. Using GRASP (GFP reconstitution across synaptic partners), we reveal potential synaptic connections between the $\mathrm{EB}$ and $\mathrm{MB}$ in regions covering both the presynaptic and postsynaptic sites of EB neurons, suggesting the presence of bidirectional connections between these two important brain structures. These findings suggest the existence of direct connections between the $\mathrm{MB}$ and EB, and provide new insights into the neural circuit basis for olfactory labile memory in Drosophila.

\section{Introduction}

Drosophila melanogaster is a simple but powerful animal model for research on learning and memory, as its behavioral profiles and their underlying neural circuits have been investigated in depth. The mushroom body (MB), for example, is well known for its essential role in olfactory memory (McGuire et al., 2001; Pascual and Preat, 2001). In Drosophila, olfactory aversive middle-term memory (MTM) is constituted by two components, anesthesia-resistant memory (ARM) and anesthesia-sensitive memory (ASM), which have different sensitivities to cold shockinduced anesthesia (Folkers et al., 1993; Waddell et al., 2000; Knapek et al., 2010,2011). Many reports have shown that the MB is responsible for the formation and modulation of ASM (Krashes et al., 2007; Schwaerzel et al., 2007; Shuai et al., 2010). It has also been reported that one type of dopaminergic neuron in the PAM cluster that sends projections to the medial tips of the MB horizontal lobes is required for the formation of ASM (Aso et al., 2010). In addition, two pairs of MB intrinsic neurons, the dorsal

\footnotetext{
Received Nov. 19, 2012; revised Jan. 28, 2013; accepted Feb. 3, 2013.

Author contributions: Z.Z., Y.L., and A.G. designed research;Z.Z., X.L., and J.G. performed research; Z.Z. analyzed data; Z.Z., Y.L., and A.G. wrote the paper.

This work was supported by the 973 Program (Grant 2011 CBA00400 to A.G.), the National Science Foundation of China (Grants 30921064, 90820008, and 31130027 to A.G., Grants 31070956 and 91132709 to Y.L.), the One Hundred Talents Project of the CAS (KSCX2-YW-R-156 to Y.L.), and the "Strategic Priority Research Program" of the Chinese Academy of Sciences (XDB02040100). The funding bodies had no role in study design, data collection and analysis, decision to publish, or preparation of the manuscript. We thank Dr. Scott Waddell, Li Liu, Yi Rao, Stephan Sigrist, Takaomi Sakai, Frederick Wolf, Kristen Scott, and the Bloominton Stock Center for generously providing fly strains, and Joy Fleming for manuscript editing. We also thank Wei Yi for help with experimental design and discussion of the manuscript, and Hao Li, Zhengchang Lei, and Jingwu Hou for technical help.

The authors declare no competing financial interests.

Correspondence should be addressed to either Aike Guo or Yan Li, Institute of Biophysics, 15 Datun Road, Chaoyang District, Beijing 100101, People's Republic of China, E-mail: akguo@ion.ac.cn or liyan@ibp.ac.cn.

DOI:10.1523/JNEUROSCI.5365-12.2013

Copyright $\odot 2013$ the authors $\quad 0270-6474 / 13 / 335175-07 \$ 15.00 / 0$
}

paired medial (DPM) and the anterior paired lateral (APL) neurons, have been reported to play a role in the modulation of ASM (Waddell et al., 2000; Keene et al., 2006). DPM neurons are suggested to both receive from and transmit to $\mathrm{MB}$ neurons and are involved in $3 \mathrm{~h}$ memory consolidation (Keene et al., 2006), whereas APL-DPM heterotypic gap junctions are required for $3 \mathrm{~h}$ ASM formation (Wu et al., 2011). Whether there are other structures outside of the MB involved in the modulation of ASM is still unclear.

We examined one brain structure located just posterior to the $\mathrm{MB}$, the ellipsoid body (EB). The EB is the anterior part of the central complex, and the characteristic doughnut structure of the EB is composed of four classes of large-field ring neurons (R1-R4) (Hanesch et al., 1989; Renn et al., 1999). One recent study reported that the NMDA receptors are required in the EB for olfactory long-term memory (LTM) consolidation (Wu et al., 2007). Here we demonstrate that the EB is also involved in the modulation of olfactory MTM, raising the possibility that the EB may have connections to the neural circuits of olfactory learning and memory. Given that the $\mathrm{MB}$ is the center for olfactory learning and memory, we wondered whether there could be direct connections between the EB and $\mathrm{MB}$.

GFP reconstitution across synaptic partners (GRASP) is a recently developed method for investigating putative synaptic connections by expressing two split components of GFP in adjacent cells. If these cells have synaptic connections and are thus close enough, GFP will be reconstituted and fluoresce under laser excitation (Feinberg et al., 2008; Gordon and Scott, 2009). Using this approach, we show that the EB and $\mathrm{MB}$ may have direct connections in both the presynaptic and postsynaptic regions of the EB.

\section{Materials and Methods}

Fly stocks. Fly strains c819-GAL4 and UAS-syt::GFP were kindly provided by Dr. Li Liu (Institute of Biophysics, Beijing, China), 5.30- 
GAL4 by Dr. Frederick Wolf (Ernest Gallo Clinic and Research Center, Emeryville, CA), and LexAop-CD4::GPF11; UAS-CD4::GFP1-10 by Dr. Kristen Scott (University of California, Berkeley, CA). UAS-TrpA1, MB247-DsRED; MB247-DsRED, MB247-LexA::VP16, UAS-mCD8:: $m C h e r r y$, and $M B-G A L 80$ were generously provided by Dr. Scott Waddell (University of Oxford, Oxford, UK). Cha ${ }^{3.3 k b}-G A L 80$ was provided by Dr. Yi Rao (Peking University, Beijing, China), UAS-D $\alpha 7:: G F P$ by Dr. Stephan Sigrist (Freie Universität Berlin, Berlin, Germany), and Gad-GAL80 by Dr. Takaomi Sakai (Tokyo Metropolitan University, Tokyo, Japan). UAS-mCD8::EGFP was obtained from the Bloomington Stock Center. The wild-type control fly strain used was $w(C S)$. All flies used in the experiments were raised on a standard medium (Guo et al., 1996) in a $12 \mathrm{~h} \mathrm{light/dark} \mathrm{cycle} \mathrm{at} 22 \pm 1^{\circ} \mathrm{C}$, $60 \%$ relative humidity.

Behavioral analysis. Olfactory aversive learning and memory tests were performed using a standard T-maze paradigm (Tully and Quinn, 1985; Zhang et al., 2008). Briefly, 2- to 5-d-old flies were collected and grouped $(\sim 100$ per vial), and training and testing were performed the next day. The odorants 4-methylcyclohexane ( $\mathrm{MCH}$, Fluka) and 3-octanol (OCT, Aldrich) were diluted in mineral oil (Thermo Fisher Scientific) at 18:10,000 and 10:10,000, respectively. For restrictive temperature experiments, flies were prewarmed at $28^{\circ} \mathrm{C}$ for $15 \mathrm{~min}$ before training. Statistical analyses were performed in Origin (OriginLab); an overall ANOVA was followed by pairwise comparisons between relevant groups using Tukey post hoc tests. All experimental groups were $n \geq 8$, unless otherwise specified.

Immunohistochemistry. Adult female flies were collected 2-5 d after eclosion and anesthetized on ice. Brains were dissected in iced PBS (containing $1.86 \mathrm{mM} \mathrm{NaH}_{2} \mathrm{PO}_{4}, 8.41 \mathrm{~mm}$ $\mathrm{NaHP}_{2} \mathrm{O}_{4}$, and $\left.175 \mathrm{~mm} \mathrm{NaCl}\right)$ and fixed in $4 \%$ paraformaldehyde (PFA) solution in PBST (0.3\% Triton X-100 in PBS) for $1 \mathrm{~h}$ at room temperature (RT). Samples were then washed three times in PBST, each time for 15 min. After blocking in 5\% normal goat serum (NGS) in PBST for $1 \mathrm{~h}$ at RT, samples were incubated with a primary antibody in blocking solution for $2 \mathrm{~d}$ at $4^{\circ} \mathrm{C}$ and washed three times in PBST at RT, each time for 15 min. Samples were incubated with a secondary antibody for another $2 \mathrm{~d}$ at $4^{\circ} \mathrm{C}$, then washed in PBST three times at RT, each time for 15 min before mounting in mounting medium (Vectashield H-1000, Vector Laboratories) for confocal imaging. Brain samples were imaged by Z-stack scanning at a step of $1 \mu \mathrm{m}$ with a Leica SP5 II confocal microscope. Z-stack images were processed for 3D reconstruction with ImageJ (National Institute of Health). Primary antibodies used in this work were 3C11 anti-synapsin at 1:100 (Developmental Studies Hybridoma Bank at the University of Iowa) and rabbit anti-GABA at 1:50 (Sigma, A2052). Secondary antibodies were Alexa 555 donkey anti-mouse IgG (Invitrogen, A31570) and Alexa 555 donkey anti-rabbit IgG (Invitrogen, A31572).
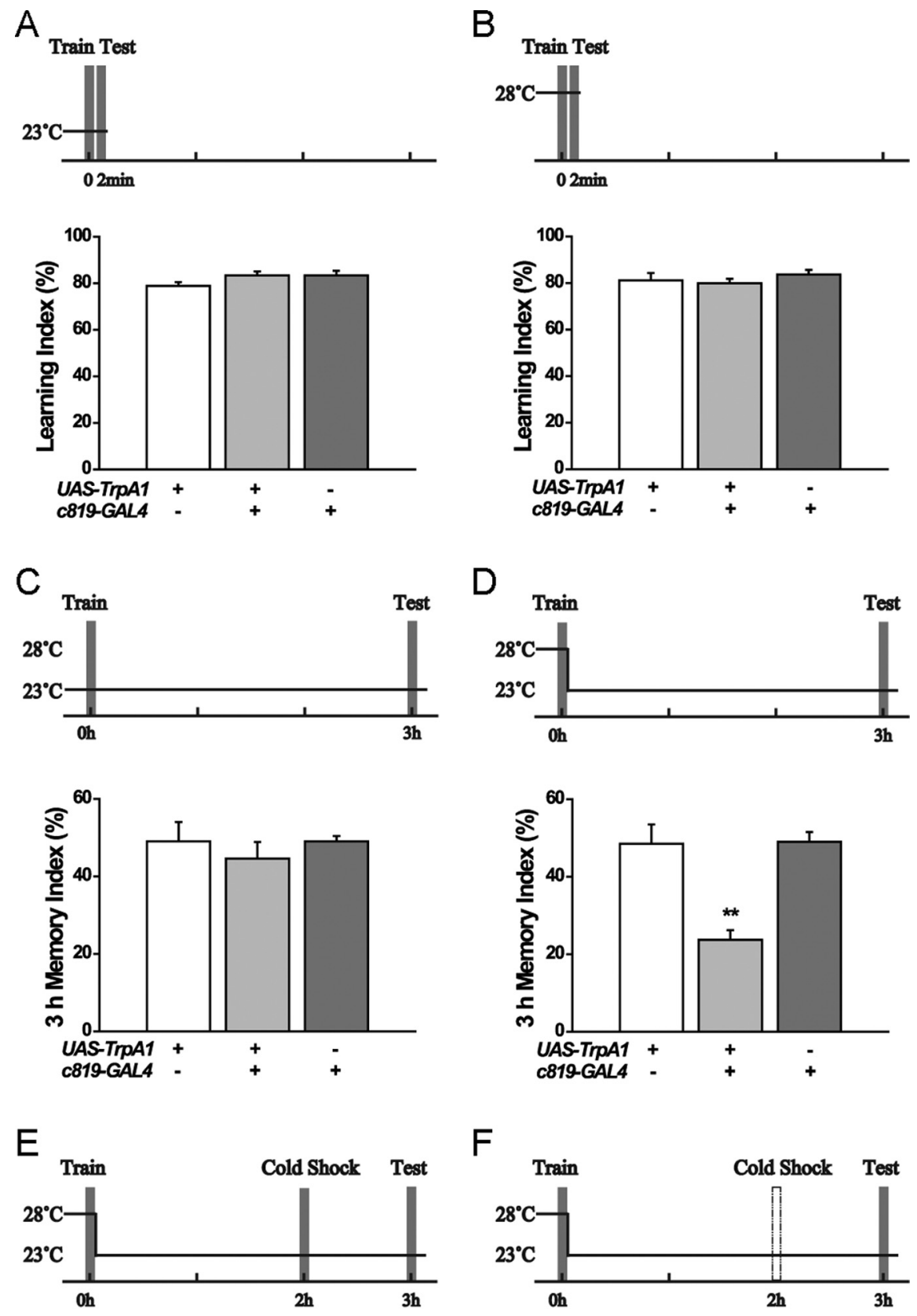

$\mathrm{F}$
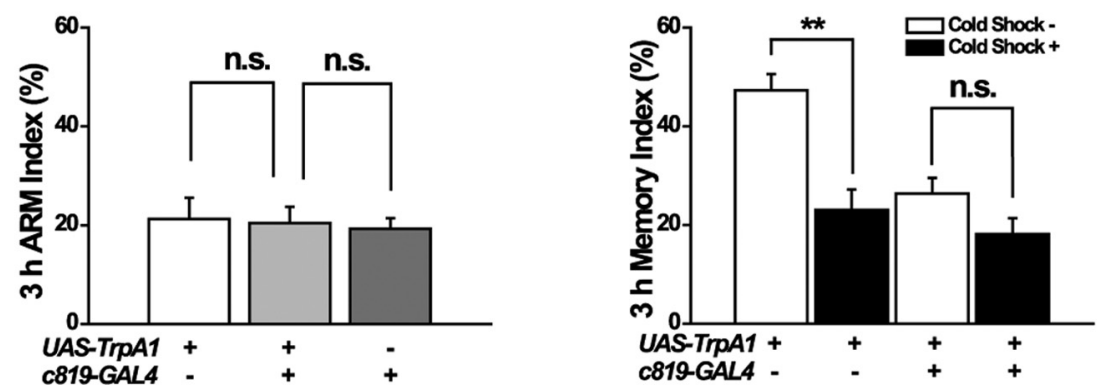

Figure 1. Activation of $c 819$ neurons by heat-inducible TrpA1 impairs $3 \mathrm{~h}$ ASM. Temperature-shift protocols are shown above each histogram. $\boldsymbol{A}, \boldsymbol{B}$, Flies were trained and tested for 2 min olfactory memory at $23^{\circ} \mathrm{C}(\boldsymbol{A})(n=10-12)$ or at $28^{\circ} \mathrm{C}(\boldsymbol{B})(n=8-15)$. $\boldsymbol{C}$, There was no difference in $3 \mathrm{~h} \mathrm{MTM}$ between experimental and control groups at $23^{\circ} \mathrm{C}(n=8-11)$. $\boldsymbol{D}$, Flies were prewarmed for $15 \mathrm{~min}$ and trained at $28^{\circ} \mathrm{C}$, then immediately shifted to $23^{\circ} \mathrm{C}$ and tested $3 \mathrm{~h}$ after conditioning. The $3 \mathrm{~h} \mathrm{MTM}$ was significantly impaired in the experimental group compared with the control group $(n=8-16)$. $\boldsymbol{E}$, Flies were trained at $28^{\circ} \mathrm{C}$, shifted immediately to $23^{\circ} \mathrm{C}$, given a cold shock at $2 \mathrm{~h}$, and then tested at $3 \mathrm{~h}$. There was no difference in $3 \mathrm{~h} \mathrm{ARM} \mathrm{between} \mathrm{experimental} \mathrm{and} \mathrm{control} \mathrm{groups}(n=8-10)$. $\boldsymbol{F}$, At $2 \mathrm{~h}$ after a $28^{\circ} \mathrm{C}$ heat-induction during training, the 2 min cold-shock treatment administered impaired 3 hmemory performance in the parental control flies, but not in $c 819>\operatorname{TrpA} 1$ flies $(n=8-12)$. Data are presented as the mean \pm SEM. ${ }^{* *} p<0.01$ analyzed by ANOVA. n.S., no significant difference. 

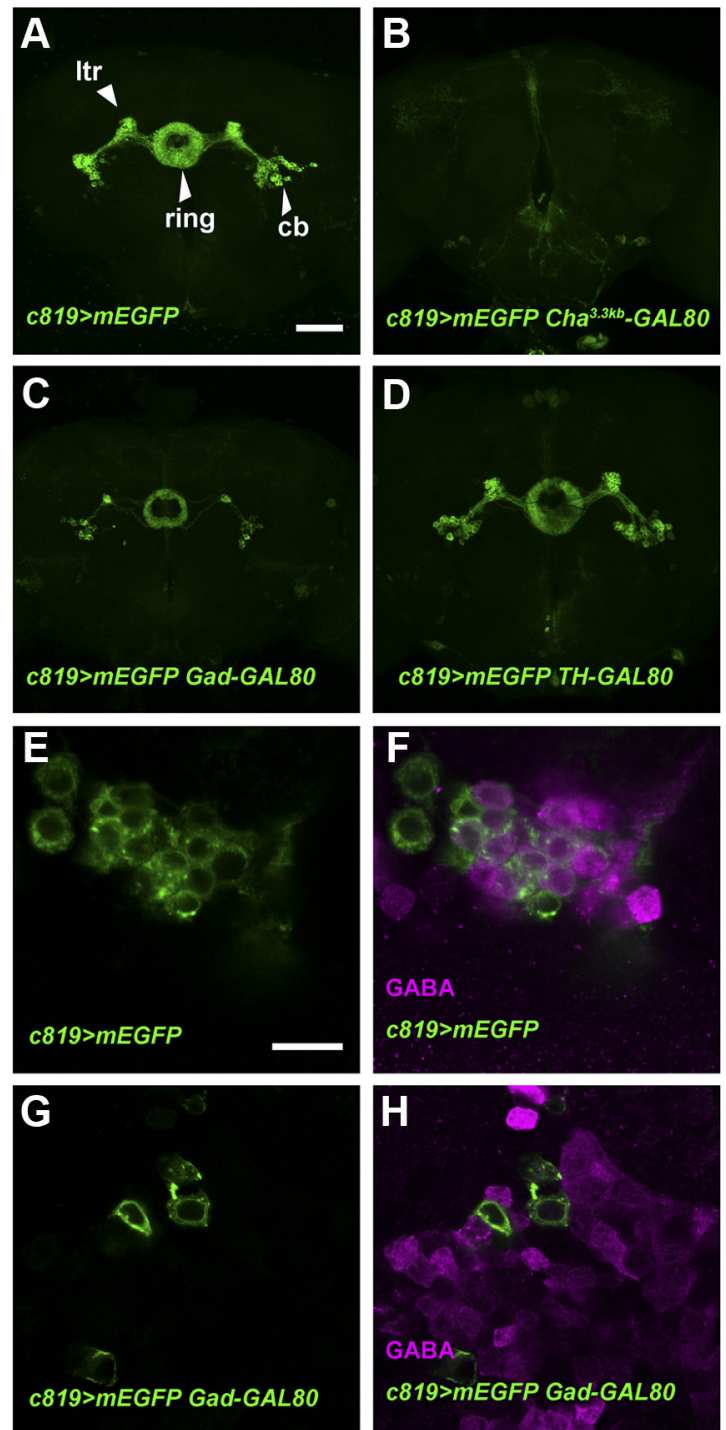
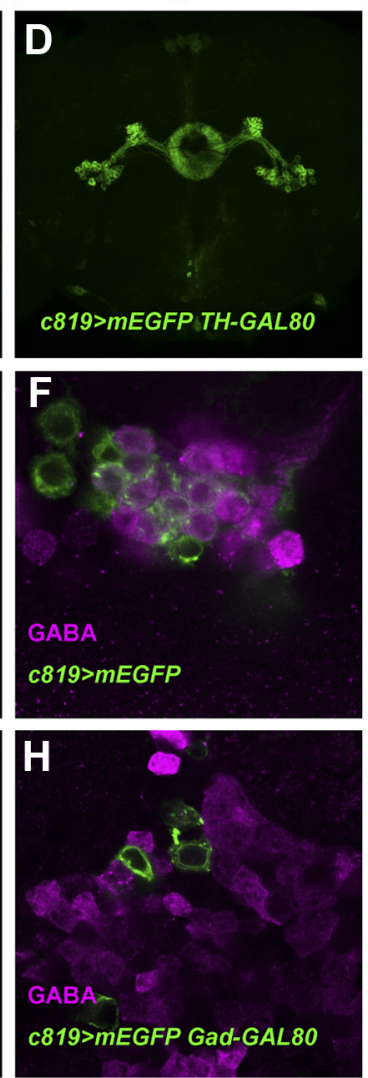

I
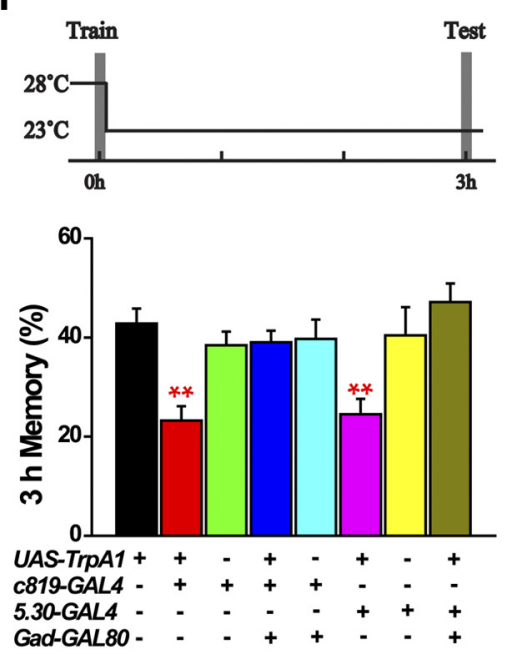

$\mathbf{J}$
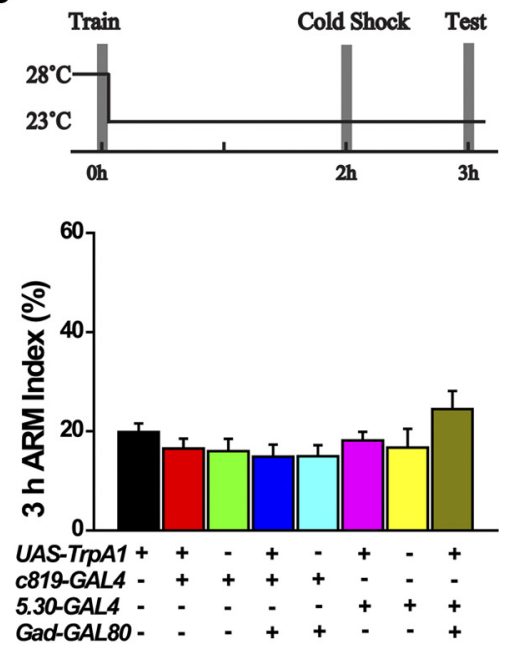

Figure 2. Activating non-GABAergic c819-EB neurons does not affect $3 \mathrm{~h}$ memory. $A$, Projection view of the $8819>m E G F P$ fly brain. Itr, Lateral triangle; $c$, cell body; ring, ring-like structure. $B-D$, Cha ${ }^{3.3 k b}$-GAL80 completely inhibited C819-driven GFP expression in the EB $(\boldsymbol{B})$, whereas Gad-GAL80 blocked the signal in a large proportion of the C819-EB neurons $(\boldsymbol{C})$ and TH-GAL80 did not appreciably inhibit c819-GAL4-driven expression (D). E, $\boldsymbol{F}$, Single-section confocal image of EB cell bodies in one hemisphere of the brain stained with anti-GABA. The GFP signal (green) shows c819-EB neurons $(\boldsymbol{E})$ and was partially merged with the anti-GABA signal (magenta) $(\boldsymbol{F}) . \mathbf{G}, \boldsymbol{H}$, With Gad-GAL80 inhibition, GFP expression in the EB neurons $(\boldsymbol{G})$ did not overlap with the GABA signal $(\boldsymbol{H}) . \boldsymbol{I}$, Heat shock during training impaired $3 \mathrm{~h}$ MTM in $\mathrm{C819}>\operatorname{TrpA1}$ and 5.30 $>\operatorname{TrpA1}$ flies. Blocking TrpA1 expression in GABAergic neurons by Gad-GAL80 eliminated this effect ( $n=8-12) . J$, There was no difference in $3 \mathrm{~h}$ ARM between all experimental and control groups $(n=8-13)$. Scale bars: $\boldsymbol{A}-\boldsymbol{D}, 50 \mu \mathrm{m} ; \boldsymbol{E}-\boldsymbol{H}, 10 \mu \mathrm{m}$. Data are presented as the mean \pm SEM. ${ }^{* *} p<0.01$ by ANOVA.

\section{Results}

Activating EB R2/R4m neurons during training specifically blocks ASM

To investigate the role of the EB in olfactory learning and memory, we expressed a temperature-sensitive cation channel TrpA1 (Hamada et al., 2008) for heat-inducible activation of R2/R4m EB neurons driven by c819-GAL4 (Renn et al., 1999). We found that $c 819>\operatorname{TrpA1}$ flies learned as well as their parental controls at $23^{\circ} \mathrm{C}$ (Fig. $1 A$ ), and temporally activating TrpAl at $28^{\circ} \mathrm{C}$ during conditioning did not affect the learning index (Fig. $1 B$ ), indicating that these flies were able to detect the odor and electric shock and couple them normally. The MTM examined at $3 \mathrm{~h}$ after conditioning was also comparable among these groups when they were not heat-activated (Fig. 1C); however, upon heatshock during training, $c 819>\operatorname{Tr} p A 1$ flies exhibited significantly lower MTM than in their parental controls $\left(F_{(2,31)}=6.3706, p=\right.$ 0.0051) (Fig. 1D). These data indicated that activating EB neu- rons during learning affected the $3 \mathrm{~h}$ MTM, instead of the immediate memory.

To determine which part of MTM was affected, we examined ARM by performing a 2 min cold shock at $2 \mathrm{~h}$ after training according to the standard paradigm (Tully et al., 1994). Results showed that these $c 819>\operatorname{TrpA1}$ flies had a normal level of ARM comparable to their parental controls (Fig. 1E). The difference between the total $3 \mathrm{~h} \mathrm{MTM}$ and the ARM, representing the level of ASM (Folkers et al., 1993), was significant in control flies $\left(F_{(1,19)}=\right.$ $21.6241, p=0.0002)$, but almost absent in $c 819>\operatorname{Tr} p A 1$ flies $\left(F_{(1,14)}=3.435, p=0.085\right)$ (Fig. $\left.1 F\right)$. Thus, activating c819-labeled EB neurons (referred to hereafter as c819-EB neurons) during training specifically impairs $3 \mathrm{~h}$ ASM while leaving ARM intact.

\section{c819-EB neurons that affect $3 \mathrm{~h}$ ASM are GABAergic}

To determine how these c819-EB neurons are involved in olfactory memory modulation, we first visualized these c819-EB neu- 
rons by expressing membrane-enhanced GFP (mEGFP) under the control of $c 819$ GAL4. Consistent with a previous report (Renn et al., 1999), we observed strong expression in the EB R2/R4m neurons, which consist of cell bodies, RF tracts, lateral triangles, lateral $\mathrm{EB}$ tracts, and a ringlike structure (Fig. 2A).

To examine the neurochemistry of these EB neurons, we combined c819GAL4 with three GAL80 lines respectively: Cha ${ }^{3.3 k b}-G A L 80$ in cholinergic neurons (Kitamoto, 2002), Gad-GAL80 in GABAergic neurons (Sakai et al., 2009), and TH-GAL80 in most of the dopaminergic neurons (Sitaraman et al., 2008). As shown in Figure 2, $A$ and $B, C h a^{3.3 k b}$ GAL80 completely blocked c819 expression in the EB region, suggesting that all the c819-EB neurons are likely cholinergic. c819-driven mEGFP expression was inhibited by Gad-GAL80 in a large portion of c819-EB neurons (Fig. 2C), whereas TH-GAL80 did not affect the expression pattern (Fig. 2D). It has been reported that some EB neurons are GABAergic (Hanesch et al., 1989; Kahsai and Winther, 2011; Kahsai et al., 2012). We counted the cell number of c819-EB neurons in both hemispheres of the brain $(n=15)$ to be $31.9 \pm 3.0$ and $31.8 \pm 2.4$ on the left and right sides, respectively. With the suppression of Gad-GAL80, only $10.0 \pm 1.9$ and $10.5 \pm 2.0$ GFP-labeled neurons remained in the left and right hemispheres. We further performed immunostaining with GABA antibody and detected GABA expression in a portion of the c819-EB cells (Fig. 2E,F). Furthermore, Gad-GAL80 completely inhibited mEGFP expression in GABA-positive neurons (Fig. 2G,H). Thus, our results demonstrate that approximately two-thirds of the c819-EB neurons are GABAergic, and that Gad-GAL80 can sufficiently suppress c819-GAL4 activity in these GABAergic neurons.

We then asked whether these GABAergic neurons are responsible for the $3 \mathrm{~h}$ MTM impairment that we observed in c819>TrpA1 flies. Consistently, heat induction of TrpA1 in c819-EB neurons during conditioning impaired 3 h memory significantly $\left(F_{(4,39)}=6.2349, p=0.0006\right)$; however, blocking TrpA1 expression in GABAergic neurons with Gad-GAL80 abolished this effect as these flies exhibited comparable $3 \mathrm{~h}$ memory to their parental controls (Fig. 2I). 5.30-GAL4 has been shown to have a similar expression pattern in the EB as c819-GAL4 (Kong et al., 2010), and we confirmed its expression pattern in EB R2/R4m neurons (data not shown). We found that activating 5.30-EB neurons by heat-induced TrpA1 during training also impaired $3 \mathrm{~h}$ memory, and this effect could also be eliminated by Gad-GAL80 (Fig. 2I). Thus, our results demonstrate that a group of GABAergic R2/R4m EB neurons is responsible for the suppression of MTM.
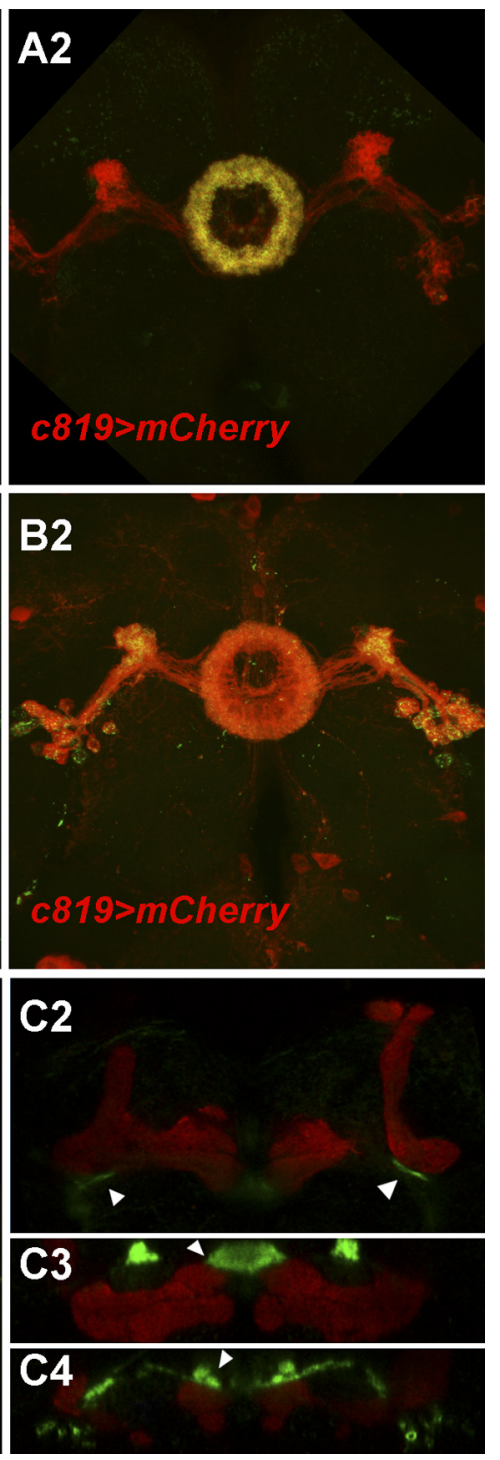

Figure 3. Distribution of presynaptic and postsynaptic regions in c819-EB neurons. A1, $\mathbf{A 2}$, Presynaptic regions labeled by Syt::GFP (green) mainly localized to the ring area of c819-EB neurons shown by mCherry (red) in (A2). B1, B2, Postsynaptic regions labeled by D $\alpha 7:: G F P$ (green) distributed to the whole neuron shown by mCherry (red) in B2. C1-C4, MB247-DsRED (red) and MGFP (green) showed MB and EB structures, respectively, which were close together in some regions (arrowheads). C1 $_{\text {, }}$ Confocal projection of the brain frontal view. (2-C4, Single section of the volume view (C2 was a coronal section and C3, C4 were horizontal sections). Scale bars, $50 \mu \mathrm{m}$.

We next analyzed the memory component by introducing a cold-shock treatment and consistently found that ARM scores had no difference in all experimental and control groups (Fig. $2 J$ ), indicating that the reduction in MTM was mainly in ASM. Together, our results demonstrate that a group of GABAergic neurons in the EB interferes with olfactory memory consolidation, specifically affecting ASM, the labile component of MTM.

\section{GRASP signals suggest direct connections between MB247} and c819-EB neurons

To investigate the synaptic distribution of EB neurons, we expressed GFP-tagged synaptotagmin (Syt) and nAChR-D $\alpha 7$ (D $\alpha 7)$ under $c 819-G A L 4$ control. Syt is a major $\mathrm{Ca}^{2+}$ sensor for synaptic vesicle exocytosis and is mainly located in synaptic vesicle-enriched presynaptic sites (Zhang et al., 2002), whereas $\mathrm{D} \alpha 7$ is a subunit of the nicotinic acetylcholine receptor and can 


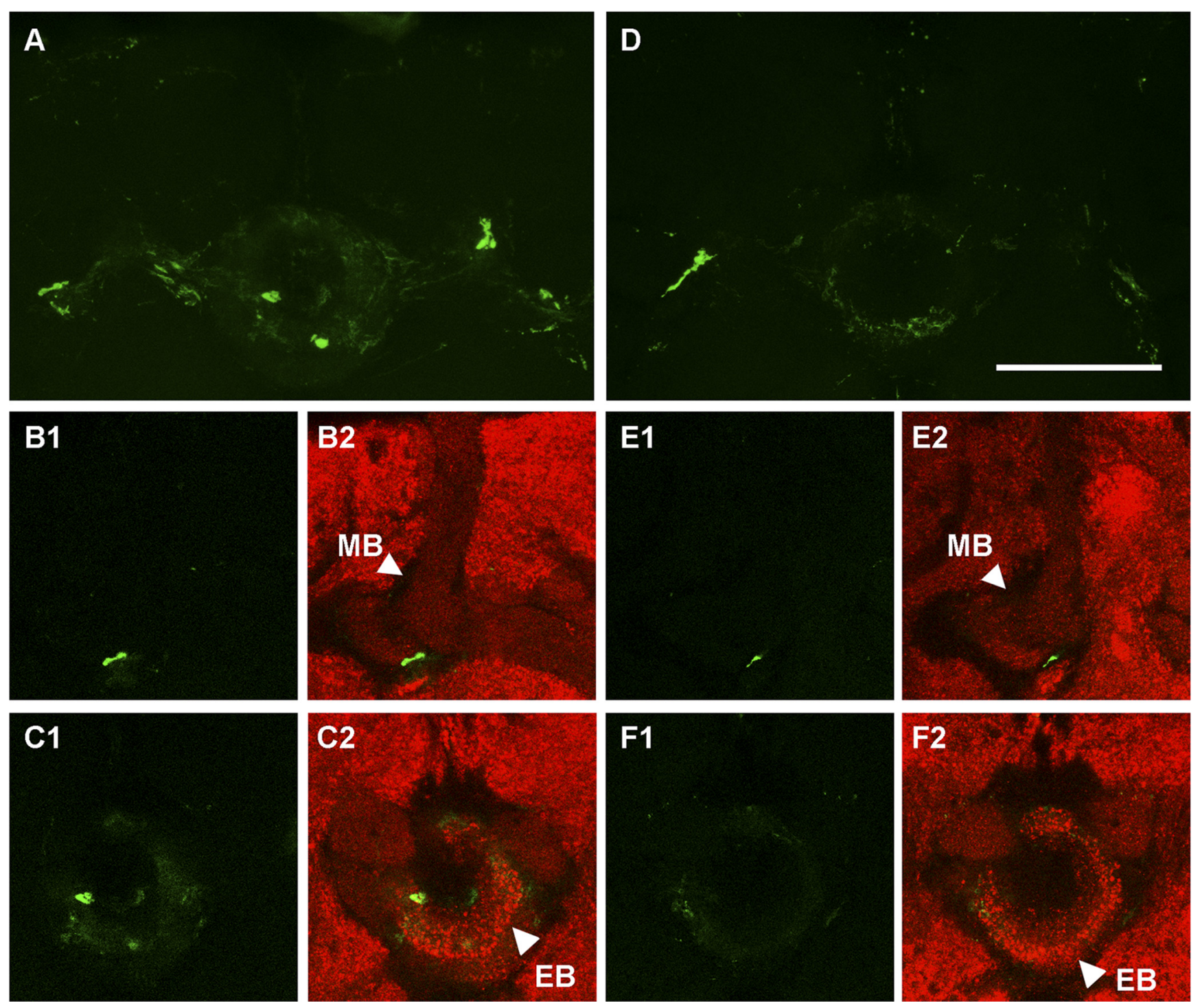

Figure 4. The EB and MB structures are close enough to form synaptic connections. $A-F$, The GRASP signal (green) reconstituted by MB 247-LexA-driven GFP11 and EB C819-GAL4-driven GFP1-10 ( $\boldsymbol{A}-\boldsymbol{C}$ ) was partially reduced by Gad-GAL80 (D-F). $\boldsymbol{A}, \boldsymbol{D}$, Projection view of the MB-EB GRASP signal. $\boldsymbol{B} 1-\boldsymbol{C}$, Single section of the MB-EB GRASP signal revealing putative connections (green) between the MB and EB in the EB RF tract area $(\boldsymbol{B 1}, \boldsymbol{B 2})$ and the ring area $(\boldsymbol{C 1}, \mathbf{C 2}) . \mathbf{E 1}-\mathbf{F 2}$, Single section of the MB-EB GRASP signal under the suppression of Gad-GAL80 showed weakened signals in both areas. Anti-synapsin counterstaining is shown in red (B2, C2, E2, F2). Scale bar, $50 \mu \mathrm{m}$.

be used as a marker for postsynapses (Grauso et al., 2002; Fayyazuddin et al., 2006; Christiansen et al., 2011). In addition, mCD8::Cherry (mCherry) was coexpressed to show the morphology of c819-EB neurons. We found that the Syt::GFP signal was restricted to the ring region, especially the anterior part, and was barely detected elsewhere (Fig. $3 A 1, A 2$ ), whereas D $\alpha 7:: \mathrm{GFP}$ labeled the ring, lateral triangle, and cell bodies, almost distributed to the whole neuron as labeled by mCherry (Fig. 3B1,B2). These findings suggest that these $\mathrm{c} 819$-EB neurons may receive information input at areas throughout the cell while sending out information mainly in the ring region.

The most prominent substructures anterior to the EB anterior region, where the presynaptic buttons of the EB are seated, are the MB horizontal lobes. We thus wondered whether these GABAergic EB neurons modulate olfactory memory via direct connections with the MB, similar to GABAergic APL neurons (Liu et al., 2007, 2009; Pitman et al., 2011; Wu et al., 2011). To examine the spatial relationship in detail, we combined c819-GAL4>mEGFP with MB247-DsRED in one fly strain (Riemensperger et al., 2005) to express green and red fluorescent proteins in these two structures, respectively. As shown in the frontal projection view (Fig. $3 C 1$ ), the cell bodies of $\mathrm{c} 819-\mathrm{EB}$ neurons were located lateral and anterior to the heels of the $\mathrm{MB}$, extending their nerve bundles from the ventral to the posterior side of the MB horizontal lobes. Using 3D reconstitution, we found that these two structures were spatially very close in some regions, for example, the EB RF tracts were adjacent to the $\mathrm{MB}$ lobe junctions as shown in the coronal section view (Fig. 3C2), and the tips of the MB horizontal lobes were anteriorly adjacent to the ring as shown in the horizontal section view (Fig. 3C3,C4). Thus, these two major brain structures may have connections in both the presynaptic and postsynaptic regions of the $\mathrm{EB}$.

To further examine whether the $\mathrm{EB}$ and $\mathrm{MB}$ are close enough to make synapses in these regions, we then performed a GRASP experiment by separately expressing the two parts of the split-GFP in c819-EB and MB247 neurons using UAS/GAL4 and LexA/LexAop dual expression systems. To completely block any potential expression of $1819-G A L 4$ in the MB, we combined MB-GAL80 (Krashes et 
al., 2007) with the GRASP system and constructed a fly strain of the following genotype: w; LexAop-CD4::spGFP11/MB-GAL80; MB247-LexA::VP16,UAS-CD4::spGFP1-10/c819-GAL4. Confocal imaging detected a strong GRASP signal in the EB (Fig. $4 A$ ), particularly in the "EB RF tracts-MB lobe junction" region (Fig. $4 B 1, B 2$ ) and the "EB ring-MB horizontal lobe tips" region (Fig. 4C1,C2). We further introduced Gad-GAL80 to this system, and the GRASP signal was significantly weakened as shown in the projection view (Fig. $4 D$ ). Signals in the above two regions were also markedly reduced with the suppression of Gad-GAL80 as shown in the single section view (Fig. 4E1-F2). These results provide further evidence to support the existence of direct connections between the EB and $\mathrm{MB}$, and indicate that these connections are largely contributed by GABAergic c819-EB neurons.

These morphological results identify two regions with potential direct connections between EB and MB neurons, and show that these two areas may contain both presynaptic and postsynaptic sites of EB neurons, suggesting that there may be bidirectional connections between these two important brain structures. Thus, our findings not only reveal a novel function of EB GABAergic neurons in olfactory memory consolidation, but also suggest that its neural circuitry possibly relies on direct connections to the $\mathrm{MB}$, the olfactory memory center of Drosophila.

\section{Discussion}

\section{The function of EB GABAergic neurons in olfactory memory}

Previous studies have shown that the EB plays an essential role in visual pattern memory, orientation memory and place learning (Pan et al., 2009; Ofstad et al., 2011; Kuntz et al., 2012), and thus it is usually considered to be a center of visual learning and memory. Interestingly, one study on NMDA receptors reported that the EB is required for olfactory long-term memory (LTM) consolidation (Wu et al., 2007); however, the underlying neural circuits remain uninvestigated. Here, our results reveal that a group of EB neurons, the c819-labeled R2/R4m neurons, plays an inhibitory role in the modulation of MTM but not the immediate memory. This points to a new function of the EB in olfactory cognition and further demonstrates that the EB could be involved in the process of olfactory aversive learning and memory from an earlier stage than previously thought.

Hanesch et al. (1989) demonstrated the presence of dense GABA-like immunoreactivity in the EB ring and RF tract suggesting that the bulk of EB neurons are GABAergic. Although this finding has been confirmed by several other studies, the function of these GABAergic neurons in cognition is still unclear. Our results further reveal that approximately two-thirds of the c819-EB neurons are GABAergic, and they play an inhibitory role in ASM modulation. The $\mathrm{GABA}_{\mathrm{A}}$ receptor, resistant to dieldrin (RDL), has been shown to be highly expressed in the MB lobes and the EB (Liu et al., 2009). It is thus possible that these EB GABAergic neurons function through RDL receptors.

\section{The neural circuits of ASM}

As a component of MTM, ASM has been suggested to be stored in the $\mathrm{MB}$ and to be modulated by MB intrinsic APL and DPM neurons ( $\mathrm{Wu}$ et al., 2011), of which the neural terminals are restricted to the $\mathrm{MB}$ (Tanaka et al., 2008). Here we report the EB, a brain structure separate from the $\mathrm{MB}$, is also involved in the modulation of ASM. We have shown that EB neurons may be both presynaptic and postsynaptic to $\mathrm{MB}$ neurons, suggesting that they may suppress $3 \mathrm{~h}$ ASM via putative direct connections between the $\mathrm{EB}$ and $\mathrm{MB}$. That the $\mathrm{MB}$ and $\mathrm{EB}$ are two discrete but possibly interconnected and interacting brain regions, sug- gests that it is important to study the process of learning and memory over a more widely distributed neural network. However, the interaction between neurons from different structures may endow the network with greater capacity for more complex activities.

It is also interesting to discover that activating c819-EB GABAergic neurons during training impaired $3 \mathrm{~h}$ ASM instead of immediate learning performance. Recently Plaçais et al. (2012) reported that blocking two pairs of dopaminergic neurons during intertrial intervals in spaced training suppresses the formation of $24 \mathrm{~h} \mathrm{LTM}$ by interfering with the slow oscillations in these dopaminergic neurons. As we have shown that bidirectional connections may exist between the $\mathrm{EB}$ and $\mathrm{MB}$, we propose that there may be a small feedback circuit between the EB and MB, which may have prolonged oscillations and therefore affect $3 \mathrm{~h}$ ASM consolidation. Further functional imaging studies may provide more clues on how this neural circuit functions.

\section{References}

Aso Y, Siwanowicz I, Bräcker L, Ito K, Kitamoto T, Tanimoto H (2010) Specific dopaminergic neurons for the formation of labile aversive memory. Curr Biol 20:1445-1451. CrossRef Medline

Christiansen F, Zube C, Andlauer TF, Wichmann C, Fouquet W, Owald D, Mertel S, Leiss F, Tavosanis G, Luna AJ, Fiala A, Sigrist SJ (2011) Presynapses in Kenyon cell dendrites in the mushroom body calyx of Drosophila. J Neurosci 31:9696-9707. CrossRef Medline

Fayyazuddin A, Zaheer MA, Hiesinger PR, Bellen HJ (2006) The nicotinic acetylcholine receptor Dalpha7 is required for an escape behavior in Drosophila. PLoS Biol 4:e63. CrossRef Medline

Feinberg EH, Vanhoven MK, Bendesky A, Wang G, Fetter RD, Shen K, Bargmann CI (2008) GFP Reconstitution Across Synaptic Partners (GRASP) defines cell contacts and synapses in living nervous systems. Neuron 57: 353-363. CrossRef Medline

Folkers E, Drain P, Quinn WG (1993) Radish, a Drosophila mutant deficient in consolidated memory. Proc Natl Acad Sci U S A 90:8123-8127. CrossRef Medline

Gordon MD, Scott K (2009) Motor control in a Drosophila taste circuit. Neuron 61:373-384. CrossRef Medline

Grauso M, Reenan RA, Culetto E, Sattelle DB (2002) Novel putative nicotinic acetylcholine receptor subunit genes, Dalpha5, Dalpha6 and Dalpha7, in Drosophila melanogaster identify a new and highly conserved target of adenosine deaminase acting on RNA-mediated A-to-I premRNA editing. Genetics 160:1519-1533. Medline

Guo A, Li L, Xia SZ, Feng CH, Wolf R, Heisenberg M (1996) Conditioned visual flight orientation in Drosophila: dependence on age, practice, and diet. Learn Mem 3:49-59. CrossRef Medline

Hamada FN, Rosenzweig M, Kang K, Pulver SR, Ghezzi A, Jegla TJ, Garrity PA (2008) An internal thermal sensor controlling temperature preference in Drosophila. Nature 454:217-220. CrossRef Medline

Hanesch U, Fischbach KF, Heisenberg M (1989) Neuronal architecture of the central complex in Drosophila melanogaster. Cell Tissue Res 257:343366. CrossRef

Kahsai L, Winther AM (2011) Chemical neuroanatomy of the Drosophila central complex: distribution of multiple neuropeptides in relation to neurotransmitters. J Comp Neurol 519:290-315. CrossRef Medline

Kahsai L, Carlsson MA, Winther AM, Nässel DR (2012) Distribution of metabotropic receptors of serotonin, dopamine, GABA, glutamate, and short neuropeptide F in the central complex of Drosophila. Neuroscience 208:11-26. CrossRef Medline

Keene AC, Krashes MJ, Leung B, Bernard JA, Waddell S (2006) Drosophila dorsal paired medial neurons provide a general mechanism for memory consolidation. Curr Biol 16:1524-1530. CrossRef Medline

Kitamoto T (2002) Conditional disruption of synaptic transmission induces male-male courtship behavior in Drosophila. Proc Natl Acad Sci U S A 99:13232-13237. CrossRef Medline

Knapek S, Gerber B, Tanimoto H (2010) Synapsin is selectively required for anesthesia-sensitive memory. Learn Mem 17:76-79. CrossRef Medline

Knapek S, Sigrist S, Tanimoto H (2011) Bruchpilot, a synaptic active zone protein for anesthesia-resistant memory. J Neurosci 31:3453-3458. CrossRef Medline 
Kong EC, Woo K, Li H, Lebestky T, Mayer N, Sniffen MR, Heberlein U, Bainton RJ, Hirsh J, Wolf FW (2010) A pair of dopamine neurons target the D1-like dopamine receptor DopR in the central complex to promote ethanol-stimulated locomotion in Drosophila. PLoS One 5:e9954. CrossRef Medline

Krashes MJ, Keene AC, Leung B, Armstrong JD, Waddell S (2007) Sequential use of mushroom body neuron subsets during Drosophila odor memory processing. Neuron 53:103-115. CrossRef Medline

Kuntz S, Poeck B, Sokolowski MB, Strauss R (2012) The visual orientation memory of Drosophila requires Foraging (PKG) upstream of Ignorant (RSK2) in ring neurons of the central complex. Learn Mem 19:337-340. CrossRef Medline

Liu X, Krause WC, Davis RL (2007) GABAA receptor RDL inhibits Drosophila olfactory associative learning. Neuron 56:1090-1102. CrossRef Medline

Liu X, Buchanan ME, Han KA, Davis RL (2009) The GABA receptor RDL suppresses the conditioned stimulus pathway for olfactory learning. J Neurosci 29:1573-1579. CrossRef Medline

McGuire SE, Le PT, Davis RL (2001) The role of Drosophila mushroom body signaling in olfactory memory. Science 293:1330-1333. CrossRef Medline

Ofstad TA, Zuker CS, Reiser MB (2011) Visual place learning in Drosophila melanogaster. Nature 474:204-207. CrossRef Medline

Pan Y, Zhou Y, Guo C, Gong H, Gong Z, Liu L (2009) Differential roles of the fan-shaped body and the ellipsoid body in Drosophila visual pattern memory. Learn Mem 16:289-295. CrossRef Medline

Pascual A, Préat T (2001) Localization of long-term memory within the Drosophila mushroom body. Science 294:1115-1117. CrossRef Medline

Pitman JL, Huetteroth W, Burke CJ, Krashes MJ, Lai SL, Lee T, Waddell S (2011) A pair of inhibitory neurons are required to sustain labile memory in the Drosophila mushroom body. Curr Biol 21:855-861. CrossRef Medline

Plaçais PY, Trannoy S, Isabel G, Aso Y, Siwanowicz I, Belliart-Guérin G, Vernier P, Birman S, Tanimoto H, Preat T (2012) Slow oscillations in two pairs of dopaminergic neurons gate long-term memory formation in Drosophila. Nat Neurosci 15:592-599. CrossRef Medline

Renn SC, Armstrong JD, Yang M, Wang Z, An X, Kaiser K, Taghert PH (1999) Genetic analysis of the Drosophila ellipsoid body neuropil: organization and development of the central complex. J Neurobiol 41:189-207. CrossRef Medline

Riemensperger T, Völler T, Stock P, Buchner E, Fiala A (2005) Punishment prediction by dopaminergic neurons in Drosophila. Curr Biol 15:1953-1960. CrossRef Medline

Sakai T, Kasuya J, Kitamoto T, Aigaki T (2009) The Drosophila TRPA channel, Painless, regulates sexual receptivity in virgin females. Genes Brain Behav 8:546-557. CrossRef Medline

Schwaerzel M, Jaeckel A, Mueller U (2007) Signaling at A-kinase anchoring proteins organizes anesthesia-sensitive memory in Drosophila. J Neurosci 27:1229-1233. CrossRef Medline

Shuai Y, Lu B, Hu Y, Wang L, Sun K, Zhong Y (2010) Forgetting is regulated through Rac activity in Drosophila. Cell 140:579-589. CrossRef Medline

Sitaraman D, Zars M, Laferriere H, Chen YC, Sable-Smith A, Kitamoto T, Rottinghaus GE, Zars T (2008) Serotonin is necessary for place memory in Drosophila. Proc Natl Acad Sci U S A 105:5579-5584. CrossRef Medline

Tanaka NK, Tanimoto H, Ito K (2008) Neuronal assemblies of the Drosophila mushroom body. J Comp Neurol 508:711-755. CrossRef Medline

Tully T, Quinn WG (1985) Classical conditioning and retention in normal and mutant Drosophila melanogaster. J Comp Physiol A 157:263-277. CrossRef Medline

Tully T, Preat T, Boynton SC, Del Vecchio M (1994) Genetic dissection of consolidated memory in Drosophila. Cell 79:35-47. CrossRef Medline

Waddell S, Armstrong JD, Kitamoto T, Kaiser K, Quinn WG (2000) The amnesiac gene product is expressed in two neurons in the Drosophila brain that are critical for memory. Cell 103:805-813. CrossRef Medline

Wu CL, Xia S, Fu TF, Wang H, Chen YH, Leong D, Chiang AS, Tully T (2007) Specific requirement of NMDA receptors for long-term memory consolidation in Drosophila ellipsoid body. Nat Neurosci 10:1578-1586. CrossRef Medline

Wu CL, Shih MF, Lai JS, Yang HT, Turner GC, Chen L, Chiang AS (2011) Heterotypic gap junctions between two neurons in the Drosophila brain are critical for memory. Curr Biol 21:848-854. CrossRef Medline

Zhang S, Yin Y, Lu H, Guo A (2008) Increased dopaminergic signaling impairs aversive olfactory memory retention in Drosophila. Biochem Biophys Res Commun 370:82-86. CrossRef Medline

Zhang YQ, Rodesch CK, Broadie K (2002) Living synaptic vesicle marker: synaptotagmin-GFP. Genesis 34:142-145. CrossRef Medline 